Supplement of Biogeosciences, 17, 3891-3901, 2020

https://doi.org/10.5194/bg-17-3891-2020-supplement

(C) Author(s) 2020. This work is distributed under

the Creative Commons Attribution 4.0 License.

(c) (1)

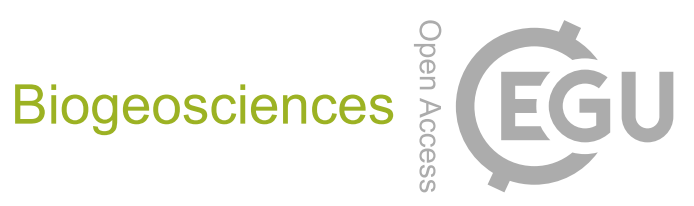

Supplement of

\title{
The stable carbon isotope signature of methane produced by saprotrophic fungi
}

Moritz Schroll et al.

Correspondence to: Moritz Schroll (moritz.schroll@geow.uni-heidelberg.de) and Katharina Lenhart (k.lenhart@th-bingen.de)

The copyright of individual parts of the supplement might differ from the CC BY 4.0 License. 


\section{Supplement}
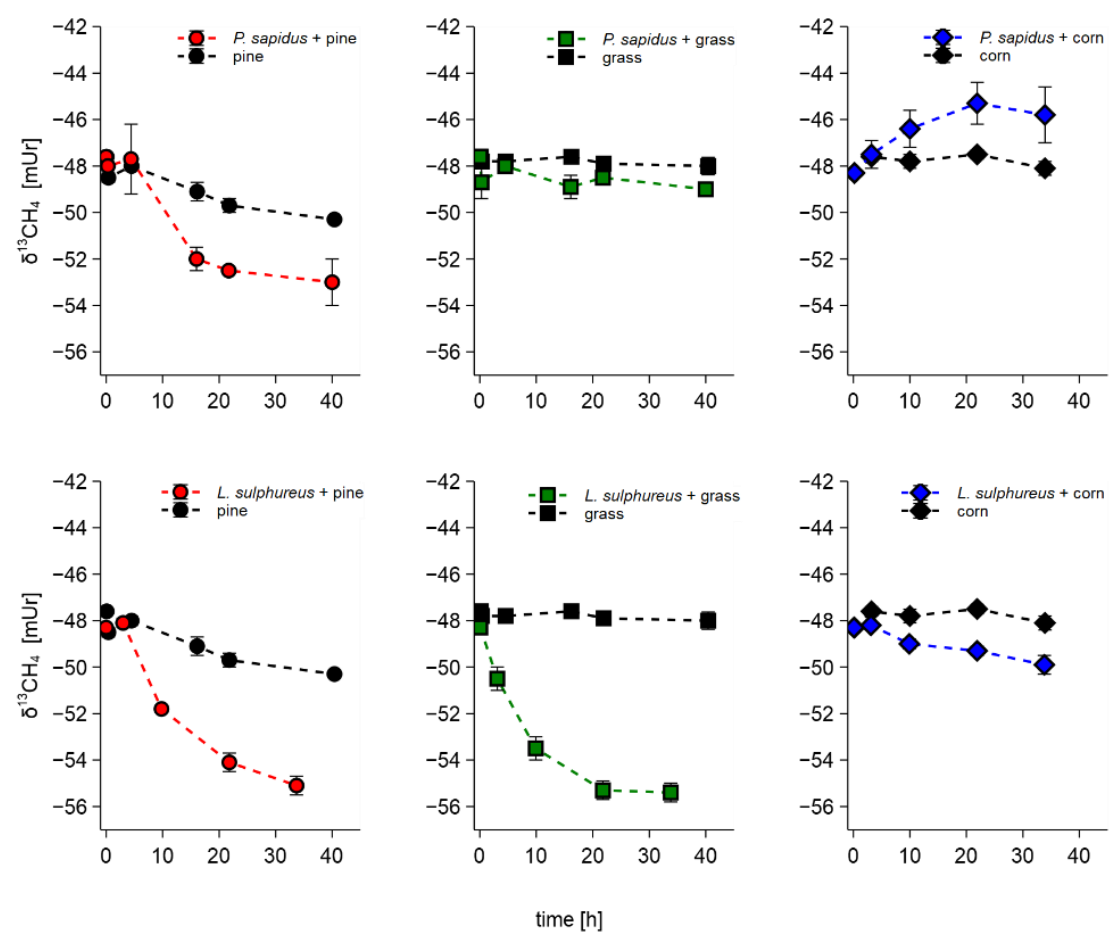

Figure S1: Stable carbon isotope values of $\mathrm{CH}_{4}$ of P. sapidus (a-c) and L. sulphureus (d-f) grown on pine, grass, and corn. Values are presented as mean values with $\mathrm{SD}(\mathrm{n}=3)$, except for $\delta^{13} \mathrm{CO}_{2}$ of $L$. sulphureus grown on corn $(\mathrm{n}=2)$.

Table S1: Statistical data including p-values of two-way ANOVA analysis performed to test the significance of "species", "substrate" effects on $\mathrm{CH}_{4}$ and $\mathrm{CO}_{2}$ emission rates, the $\mathrm{CH}_{4}: \mathrm{CO}_{2}$ emission ratios, $\delta^{13} \mathrm{C}_{-} \mathrm{CH}_{4}$ and $\delta^{13} \mathrm{C}_{-}-\mathrm{CO}_{2}$ source signatures by $P$. sapidus and $L$. sulphureus.

\begin{tabular}{cccc}
\hline & & p-value & f-value \\
\hline $\boldsymbol{\delta}^{\mathbf{1 3}} \mathbf{C}-\mathbf{C H}_{\mathbf{4}}$ & Species effect & $<0.001$ & 100 \\
& Substrate effect & $<0.001$ & 147 \\
$\boldsymbol{\delta}^{\mathbf{1 3}} \mathbf{C}^{-\mathbf{C O}_{\mathbf{2}}}$ & Species effect & 0.008 & 10 \\
& Substrate effect & $<0.001$ & 742 \\
$\mathbf{C H}_{\mathbf{4}}$ emission rates & Species effect & 0.03 & 6.5 \\
\hline
\end{tabular}




\begin{tabular}{cccc}
\hline & Substrate effect & $<0.001$ & 14 \\
$\mathbf{C O}_{2}$ emission rates & Species effect & $<0.001$ & 53 \\
& Substrate effect & $<0.001$ & 75 \\
$\mathbf{C H}_{4}: \mathbf{C O}_{2}$ emission ratio & Species effect & 0.47 & 0.55 \\
& Substrate effect & 0.07 & 3.4 \\
\hline
\end{tabular}

10 